\title{
Uso do diafragma externo na ligação entre viga de seção I e pilar tubular de seção circular
}

The use of the external diaphragm in the connection between an I beam section and tubular hollow section column

\section{Felipe Botelho Coutinho \\ Walnório Graça Ferreira \\ Macksuel Soares de Azevedo}

\section{Resumo}

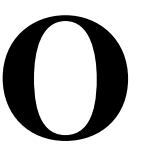

diafragma externo na ligação entre viga metálica de seção I e pilar metálico tubular de seção circular tem por objetivo o aumento na eficácia da transferência dos esforços. A proposta é dar alternativas ao uso desse sistema estrutural, reduzindo a limitação imposta por sua simples ligação ao se adicionar esse elemento, similar a um anel, que envolve o pilar e é conectado à mesa da viga. As pesquisas com diafragma externo tiveram início na década de 1970 no Japão, onde foram feitas análises teóricas e experimentais de sua aplicação. No Brasil os primeiros estudos ocorreram em 2005, porém as normas de estruturas em aço brasileiras ainda não abordam esse assunto. Neste trabalho são feitas análises numéricas da ligação com diafragma externo entre viga de seção I e pilar tubular de seção circular para diferentes larguras e espessuras desse enrijecedor, em que é constatado o considerável aumento da resistência e da rigidez da ligação.

${ }^{1}$ Felipe Botelho Coutinho ${ }^{1}$ Universidade Federal do Espírito Vitória - ES - Brasil

${ }^{2}$ Walnório Graça Ferreira 2Universidade Federal do Espírito

$$
\text { Santo }
$$

Vitória - ES- Brasil

${ }^{3}$ Macksuel Soares de Azevedo
${ }^{3}$ Universidade Federal do Espírito
Santo
Vitória - ES - Brasil

Recebido em 22/02/17

Aceito em 15/04/18

Palavras-chave: Estrutura em aço. Ligação viga-pilar. Diafragma externo.

\section{Abstract}

The external diaphragm in the connection between an I metal beam section and a hollow section tubular column is designed to increase efficiency in transfer of its efforts. This study aims at offering alternatives to the use of this structural system, reducing the limit imposed by its simple connection when this element is added, like a ring that surrounds the column and is connected to the beam flange. Studies investing the external diaphragm began in the 1970s in Japan, where theoretical and experimental analyses of its application were carried out. In Brazil, the first studies took place in 2005, but Brazilian steel structure standards have not yet addressed this issue. In this study numerical analyses were performed on connections with external diaphragm between I-beam section and hollow section tubular column for different widths and thicknesses of this stiffener. The analyses showed that there was considerable increase in the strength and stiffness of the connection.

Keywords: Steel structure. Beam-column connection. External diaphragm. 


\section{Introdução}

As ligações entre vigas e pilares metálicos desempenham um papel fundamental no comportamento global das estruturas em aço, o que proporciona um elevado e contínuo interesse da comunidade técnico-científica em avalia-las de forma mais precisa, com o objetivo de entender seu funcionamento. No entanto, sobre a ligação com diafragma externo são poucos os estudos, apesar de Kamba e Kanatani (1993) relatarem ser essa a forma mais simples de enrijecer uma ligação entre viga de seção I e pilar tubular de seção circular. Além disso, os principais comitês técnicos, Eurocode e American Institute of Steel Construction (AISC), não abordam seu dimensionamento, sendo necessária a realização de estudos para embasamento teórico de sua aplicação. Na Figura 1 é mostrado um exemplo do uso do diafragma externo entre viga de seção I e pilar tubular de seção circular.

No Brasil, apesar do crescimento do uso das estruturas tubulares, ainda são poucas as pesquisas sobre o comportamento das ligações com diafragma externo. A norma brasileira para ligações tubulares em aço, NBR 16239 (ABNT, 2013), e as principais normas internacionais, americana ANSI/AISC 360 (AMERICAN..., 2010) e europeia Eurocode 3 (EUROPEAN..., 2005a, 2005b), não fazem referência a sua utilização. As equações de dimensionamento são limitadas a recomendações do Instituto de Arquitetura do Japão (AIJ) de 1990 "Recommendations for Design and Fabrication of Tubular Structures in Steel", na seção 4.4.5, conforme tradução do japonês para o inglês por Kamba e Kanatani (1993), e ao nono manual do Cidect-DG9 (Comité International Pour Le Développement Et L'étude De La Construction Tubulaire - Design Guide 9: For Structural Hollow Section Column Connections) para ligações em perfis tubulares, escrito por Kurobane et al. (2004) - referência para este trabalho. Isso demonstra a necessidade de estudos sobre esse elemento enrijecedor, principalmente no âmbito das técnicas construtivas nacionais, e sua influência no comportamento da ligação.

O objetivo geral deste trabalho é estudar o comportamento estrutural da ligação de aço com diafragma externo entre viga de seção I e pilar tubular de seção circular a partir de modelos numéricos.

\section{Referencial teórico}

Os estudos de ligações com diafragma externo iniciaram-se com Wakabayashi, Sasaki e Kishima (1971), o qual destaca a contribuição delas no ganho da resistência. Durante os anos 1980, segundo Kurobane et al. (2004), pesquisas realizadas por Kamba e Tabuchi contribuíram consideravelmente para a equação da ligação com diafragma externo do AIJ em 1990. Já na década de 1990, destaca-se o trabalho de Kamba e Kanatani (1993), que apresenta a tradução para o inglês do capítulo da norma japonesa correspondente às ligações com diafragma externo. Kurobane et al. (2004), no início deste século, em sua publicação associada ao Cidect, apresentam uma nova equação para o cálculo da resistência da ligação com diafragma externo. No Brasil, o primeiro registro sobre o comportamento da ligação entre viga e pilar com diafragma externo é apresentado por Carvalho (2005), em que avalia numericamente a inserção do diafragma externo aparafusado à viga e constata o comportamento rígido para essa condição. Freitas (2009), através de análise numérica, investiga o comportamento das ligações entre viga de seção I e pilar tubular de seção circular, no qual avalia as influências para diferentes geometrias de pilar e viga, bem como o acréscimo do diafragma externo. Masioli (2011) avalia os resultados experimentais e numéricos da ligação sem e com diafragma externo; além disso, realiza um estudo paramétrico sobre sua inserção. Pereira (2013) discorre sobre a aplicação de equações existentes e analisa numericamente as variações de elementos estruturais - também faz uso do diafragma externo na ligação. Dessa forma nos inspira para dar sequência a este trabalho do uso do diafragma externo.

\section{Método}

O plano de trabalho para este estudo é a análise numérica da ligação de elementos metálicos com diafragma externo entre viga de seção I e pilar tubular de seção circular. $\mathrm{O}$ objetivo da investigação através do emprego do método dos elementos finitos é a possibilidade de expandir para diferentes geometrias o conhecimento de um dado comportamento estrutural, o que permite a redução substancial de tempo e de custo da solução quando comparados com modelagem experimental. O modelo computacional/numérico empregado é validado comparando-se os resultados com aqueles de experimento sem diafragma externo realizado por Masioli (2011). Na sequência, a ligação com o diafragma externo é inserida com os mesmos parâmetros geométricos do Cidect-DG9 (KUROBANE et al., 2004), referência para este trabalho. Para a realização desta pesquisa é utilizado o programa comercial baseado no método dos elementos finitos Ansys 17.0. 


\section{Experimento de Masioli (2011)}

O experimento para validação do modelo numérico deste trabalho é o protótipo TCR-W de Masioli (2011), ligação tipo T, conforme ilustrado na Figura 2.

O fato de haver solda na ligação entre a viga e o pilar facilita a análise numérica e o posterior acréscimo do diafragma externo. Além disso, Masioli (2011) não considera força axial no pilar.
Nas Tabelas 1 e 2 são apresentadas as propriedades geométricas dos perfis utilizados na análise experimental.

Na Tabela 3 são apresentados os resultados da resistência dos aços obtidos por Masioli (2011).

Na Figura 3 é mostrado o comportamento do deslocamento na extremidade da viga no ponto de controle, com afastamento da ponta em $100 \mathrm{~mm}$, que corresponde à posição do enrijecedor vertical neste mesmo local tem-se o atuador hidráulico aplicando a força.

\section{Figura 1 - Aplicação do diafragma externo na ligação, aeroporto de Auckland, Nova Zelândia}

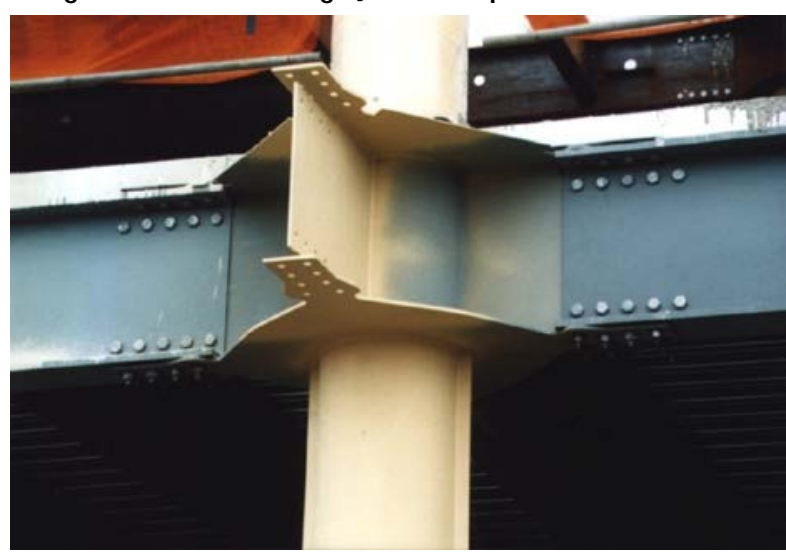

Fonte: Atlas Tube (2013).

Figura 2 - Geometria do protótipo de Masioli (2011), medidas em mm

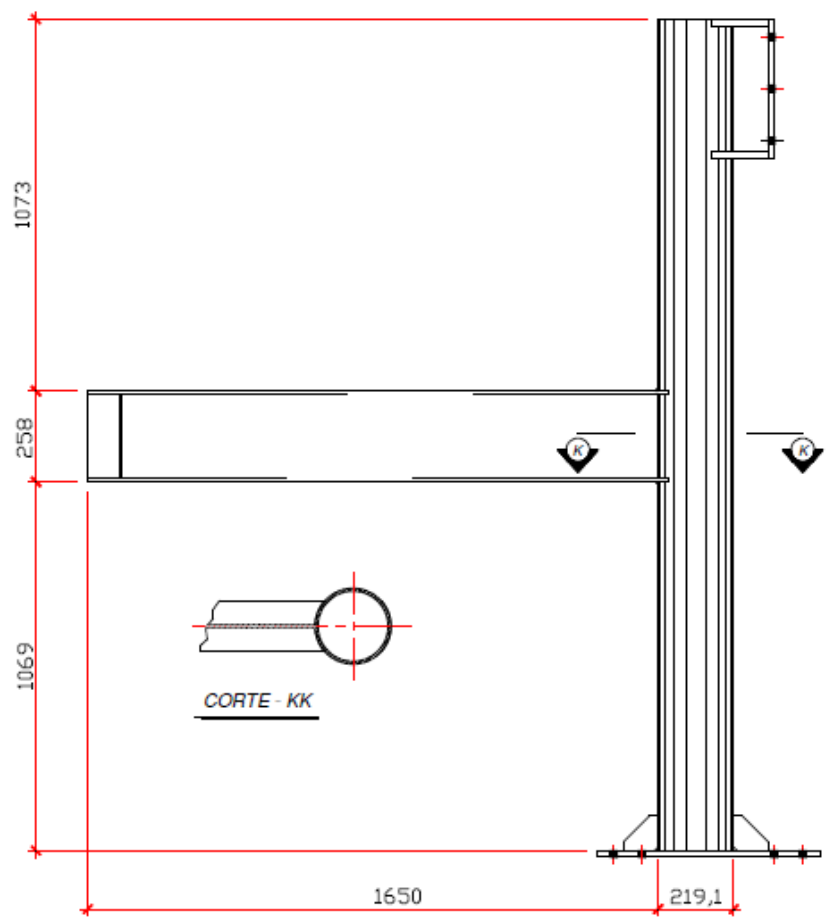

Fonte: Masioli (2011). 
Tabela 1 - Propriedades geométricas da viga de seção I

\begin{tabular}{c|c|c|c|c|c|c|c|c|c}
\hline Perfil & $\begin{array}{c}\text { Massa linear } \\
(\mathbf{k g} / \mathbf{m})\end{array}$ & $\begin{array}{c}\text { Área } \\
\left(\mathbf{c m}^{2}\right)\end{array}$ & $\begin{array}{c}\mathbf{d} \\
\mathbf{( m m})\end{array}$ & $\begin{array}{c}\mathbf{t}_{\mathbf{w}} \\
(\mathbf{m m})\end{array}$ & $\begin{array}{c}\mathbf{h}_{\mathbf{w}} \\
(\mathbf{m m})\end{array}$ & $\begin{array}{c}\mathbf{t}_{\mathbf{f}} \\
(\mathbf{m m})\end{array}$ & $\begin{array}{c}\mathbf{b}_{\mathbf{f}} \\
(\mathbf{m m})\end{array}$ & $\begin{array}{c}\mathbf{I}_{\mathbf{x}} \\
\left(\mathbf{c m}^{\mathbf{4}}\right)\end{array}$ & $\begin{array}{c}\mathbf{W}_{\mathbf{x}} \\
\left(\mathbf{c m}^{\mathbf{4}}\right)\end{array}$ \\
\hline $258 \times 32$ & 32,34 & 41,2 & 258 & 6,1 & 239,8 & 9,1 & 146 & 4.818 & 374 \\
\hline
\end{tabular}

Tabela 2 - Propriedades geométricas do pilar tubular de seção circular

Nota: Legenda:

\begin{tabular}{c|c|c|c|c|c}
\hline $\mathbf{d}_{\mathbf{0}} \mathbf{( \mathbf { m m } )}$ & $\mathbf{t}_{\mathbf{d}} \mathbf{( \mathbf { m m } )}$ & Massa Linear $\mathbf{( k g} / \mathbf{m})$ & Área $\mathbf{( \mathbf { c m } ^ { 2 } )}$ & $\mathbf{I} \mathbf{( \mathbf { c m } ^ { \mathbf { 4 } } )}$ & $\mathbf{W}_{\mathbf{x}}\left(\mathbf{c m}^{\mathbf{3}}\right)$ \\
\hline 219,1 & 8,2 & 42,5 & 54,2 & 3.020 & 276 \\
\hline
\end{tabular}

\footnotetext{
d - altura total da viga I;

$t_{w}$ - espessura da alma da viga $l_{\text {; }}$

$\mathrm{h}_{\mathrm{w}}$ - altura da alma da viga I;

$t_{f}$ - espessura da mesa da viga $l_{\text {; }}$

$\mathrm{b}_{f}$ - largura da mesa da viga l;

I - momento de inércia;

$\mathrm{I}_{\mathrm{x}}$ - momento de inércia em relação ao eixo $\mathrm{x}$;

$\mathrm{W}_{\mathrm{x}}$ - módulo de resistência à flexão em relação ao eixo $\mathrm{x}$;

$\mathrm{d}_{0}$ - diâmetro do pilar; e

$t_{d}$ - espessura da parede do pilar.
}

Tabela 3 - Resistência média dos aços

\begin{tabular}{c|c|c}
\hline Elemento & $\mathbf{f}_{\mathbf{y}} \mathbf{( M P a )}$ & $\mathbf{f}_{\mathbf{u}} \mathbf{( M P a )}$ \\
\hline Viga & 400,0 & 513,0 \\
Pilar & 330,0 & 473,0 \\
Diafragma externo & 385,0 & 468,0 \\
\hline
\end{tabular}

Figura 3 - Reação da viga em balanço (em destaque o ponto de controle [PC] do ensaio)

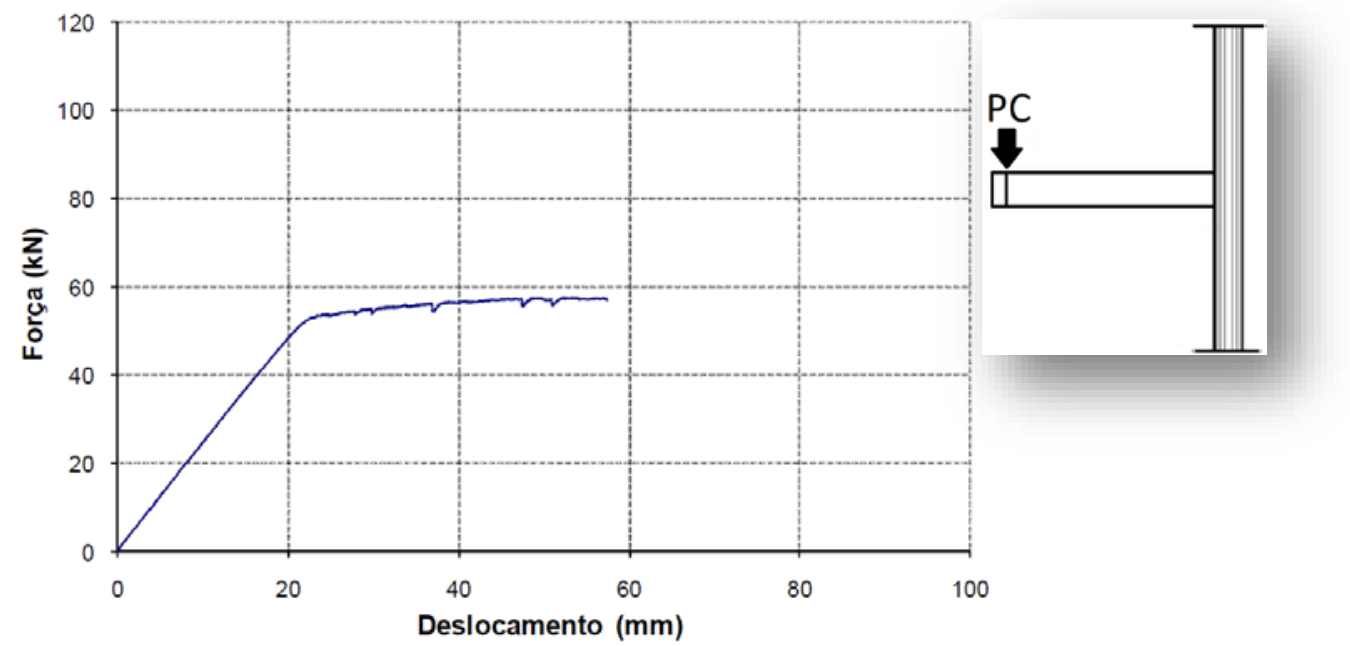

Fonte: Masioli (2011).

\section{Modelo numérico}

Nesta análise é adotado um modelo tridimensional utilizando o programa de elementos finitos ANSYS - 17.0. A sequência é gerar inicialmente o modelo numérico TCR-W de Masioli (2011) e, em seguida, fazer o acréscimo do diafragma externo na ligação.

\section{Formatação numérica do experimento de Masioli (2011)}

Para o experimento de Masioli (2011), em uma tentativa de simplificar o modelo e de reduzir o custo computacional quando da análise paramétrica, adotam-se elementos planos (poucos nós) para representar o volume. Nesse sentido, é assumida a viga como um agrupamento de placas, correspondentes às mesas e à alma - já o pilar equivale à geometria de casca, devido a sua seção 
vazada e à espessura de parede fina. Dessa forma, para a simulação numérica deste trabalho é utilizado o elemento Shell281, conforme ANSYS (1999), governado pela teoria de Mindlin-Reissner, derivado da análise de estruturas de placa fina e moderadamente espessa. Além disso, ele é compatível com grandes rotações e deformações não lineares, constituído de um elemento com oito nós $(i, j, k, l, m, n, o, p)$ e seis graus de liberdade cada (translação e rotação nas direções $x, y$ e $z$ ), de acordo com o apresentado na Figura 4.

A escolha desse tipo de elemento em detrimento a outro mais simples, com quatro nós (Shell181 da biblioteca do ANSYS (1999), decorre do surgimento de elementos triangulares na interface entre a mesa da viga e o pilar em função da geração automática da malha - geometria não recomendada para esse elemento. Para o mapeamento considerase uma maior concentração dos elementos nas regiões próximas à ligação, principal interesse deste estudo, seguindo o mesmo critério de Masioli (2011) na parte numérica de seu trabalho.

A razão da dimensão entre o tamanho do elemento refinado e o padrão corresponde a $1 / 4$, cuja relação, em um estudo preliminar, apresentou a melhor compatibilidade. Quando considerado o diafragma externo, essa razão com a malha padrão é igual a 1/5, devido a sua geometria na ligação com a mesa da viga. O ANSYS - v. 17, em sua distribuição automática, pode reduzir os tamanhos preestabelecidos dos elementos para uma melhor disposição.

Para a discretização da malha de elementos finitos é adotada a situação ótima para o mínimo do esforço computacional e a pequena diferença, entre as iterações, da força máxima resistente na extremidade da viga. O valor inicial para a dimensão padrão do elemento é de $200 \mathrm{~mm}$, em função da altura da viga, sendo reduzido a cada 10 mm até $100 \mathrm{~mm}$, e, após esse valor, com variação de $5 \mathrm{~mm}$ até a dimensão de $50 \mathrm{~mm}$, dando continuidade nessa redução até que se atinja o nível proposto para convergência - menor do que $1 \%$. Também é apresentado nos resultados o tempo de processamento para uma máquina com quatro núcleos exclusivos para o processamento dos dados, com 3,4 GHz cada e memória RAM DDR3 de 8,0 Gb. A Figura 5 mostra o modelo TCR-W para a geometria inicial com o elemento Shell281 para os dois tipos de malhas, nas dimensões iniciais: padrão (extremidades do pilar e ponta em balanço da viga), igual a 200 mm; e refinado (região da ligação), com $50 \mathrm{~mm}$.

As imperfeições geométricas não são consideradas para este modelo em virtude do tipo do carregamento e da região resistente ao esforço com a face do pilar atuando como uma mola. Para a resistência do aço é adotada a curva tensãodeformação de quatro pontos, mesma consideração feita por Maggi (2004) em seu estudo numérico, conforme a Tabela 4 e como representadas nas Figuras 6 e 7 as curvas tensão-deformação.

Para as condições de contorno é adotado o mesmo conceito de Masioli (2011) na parte numérica de seu trabalho, em que o autor considera nas extremidades do pilar sua restrição total ao deslocamento e à rotação, enquanto a viga em balanço é impedida de transladar fora do plano principal em virtude do atuador hidráulico, conforme demonstrado na Figura 8.

\section{Diafragma externo}

Após a conceituação do modelo numérico do experimento de Masioli (2011) é feita a inserção do diafragma externo, que tem por base os mesmos parâmetros do Cidect-DG9 (KUROBANE et al., 2004), conforme apresentado nas Figuras 9 e 10.

\section{Figura 4 - Elemento Shell281}

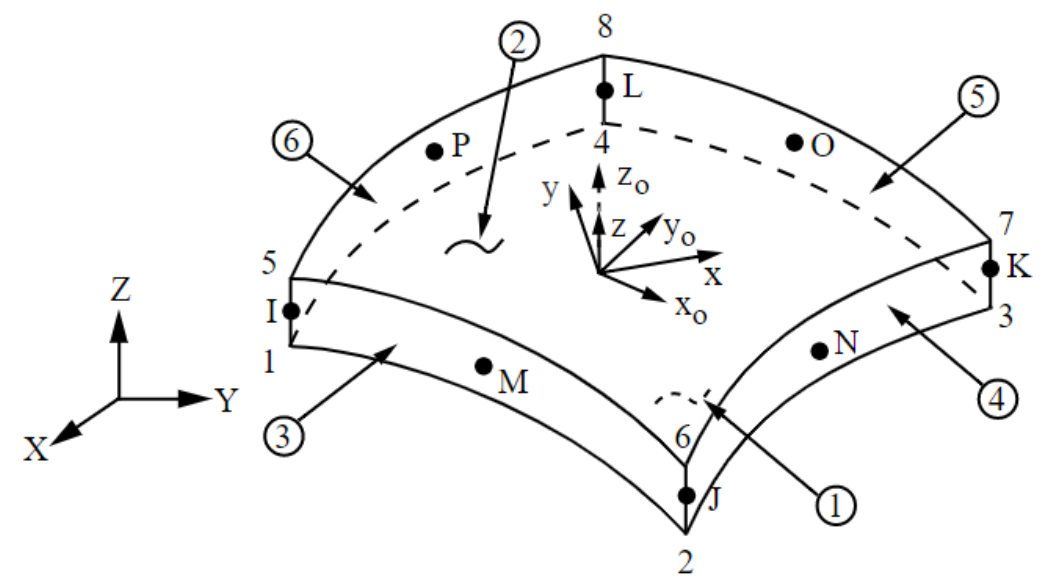

Fonte: ANSYS (1999). 
Figura 5 - Distribuição dos elementos no modelo TCR-W (a) e o modelo numérico em (b)

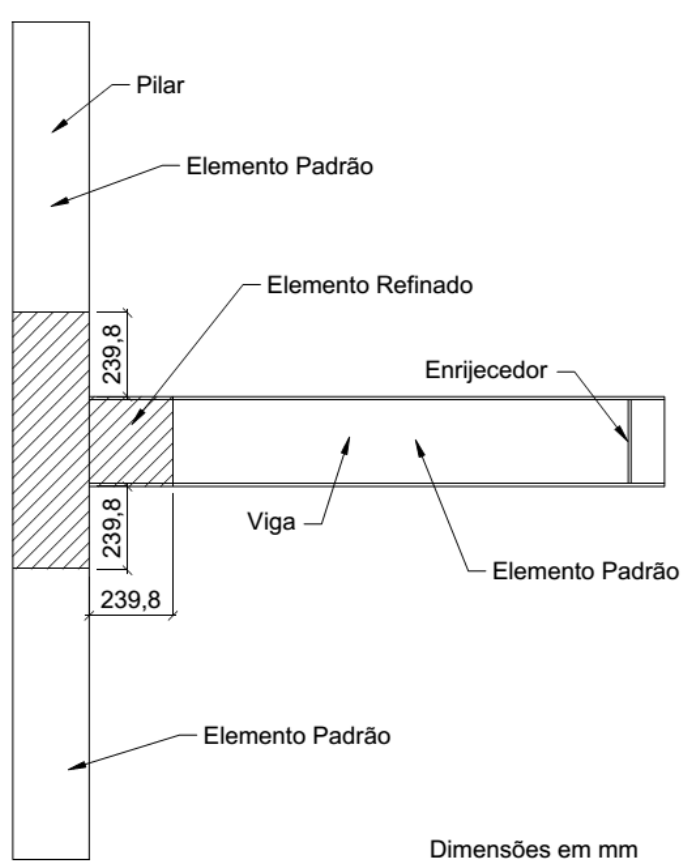

(a)

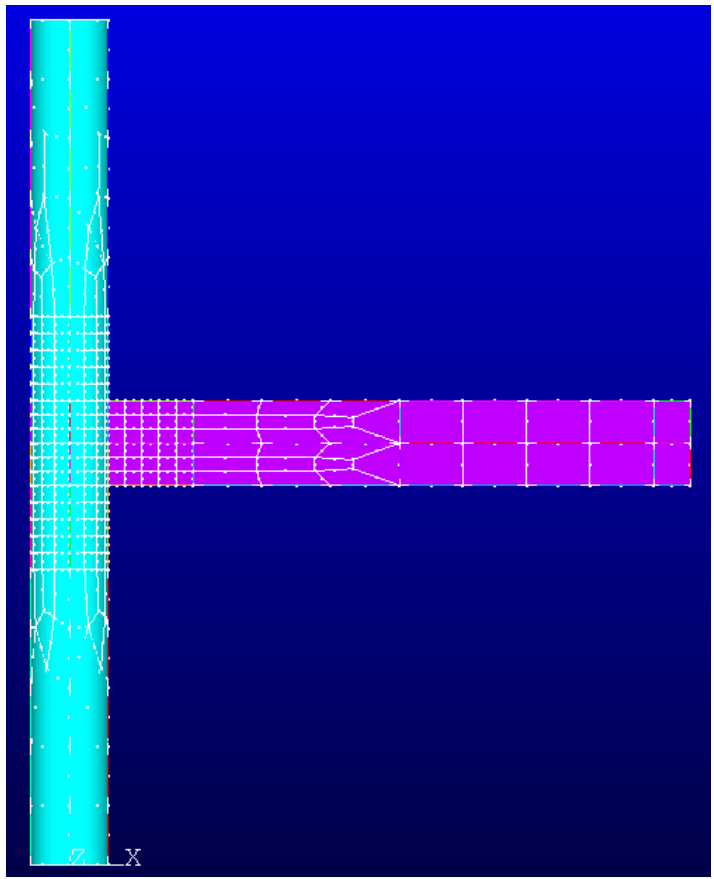

(b)

Figura 6 - Destaque para a ligação

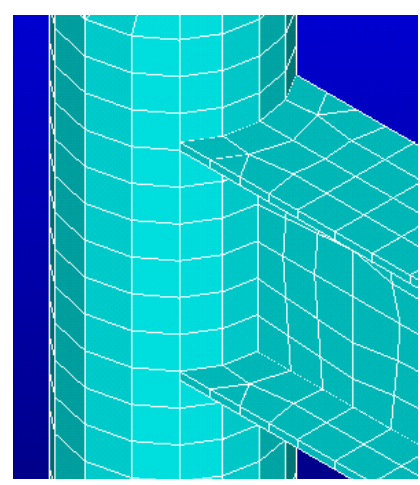

Tabela 4 - Comportamento multilinear do aço

\begin{tabular}{|c|c|c|}
\hline Ponto & Tensão $(\sigma)$ & 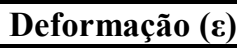 \\
\hline 1 & $\mathrm{f}_{\mathrm{y}}$ & $\varepsilon_{\mathrm{y}}$ \\
\hline 2 & $\mathrm{f}_{\mathrm{y}}$ & $9 \varepsilon_{\mathrm{y}}$ \\
\hline 3 & $\mathrm{f}_{\mathrm{y}}+0,5\left(\mathrm{f}_{\mathrm{u}}-\mathrm{f}_{\mathrm{y}}\right)$ & $22 \varepsilon_{\mathrm{y}}$ \\
\hline 4 & $\mathrm{f}_{\mathrm{u}}$ & $60 \varepsilon_{\mathrm{y}}$ \\
\hline
\end{tabular}


Figura 7 - Propriedades mecânica dos aços

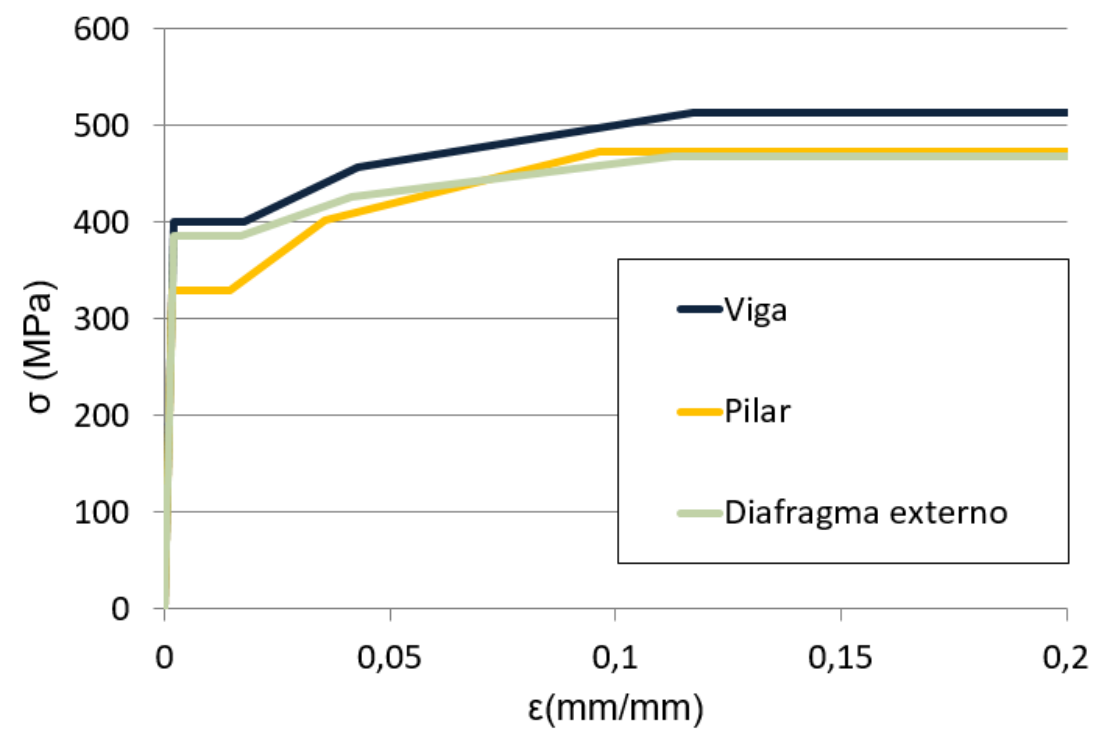

Figura 8 - Experimento TCR-W de Masioli (2011)

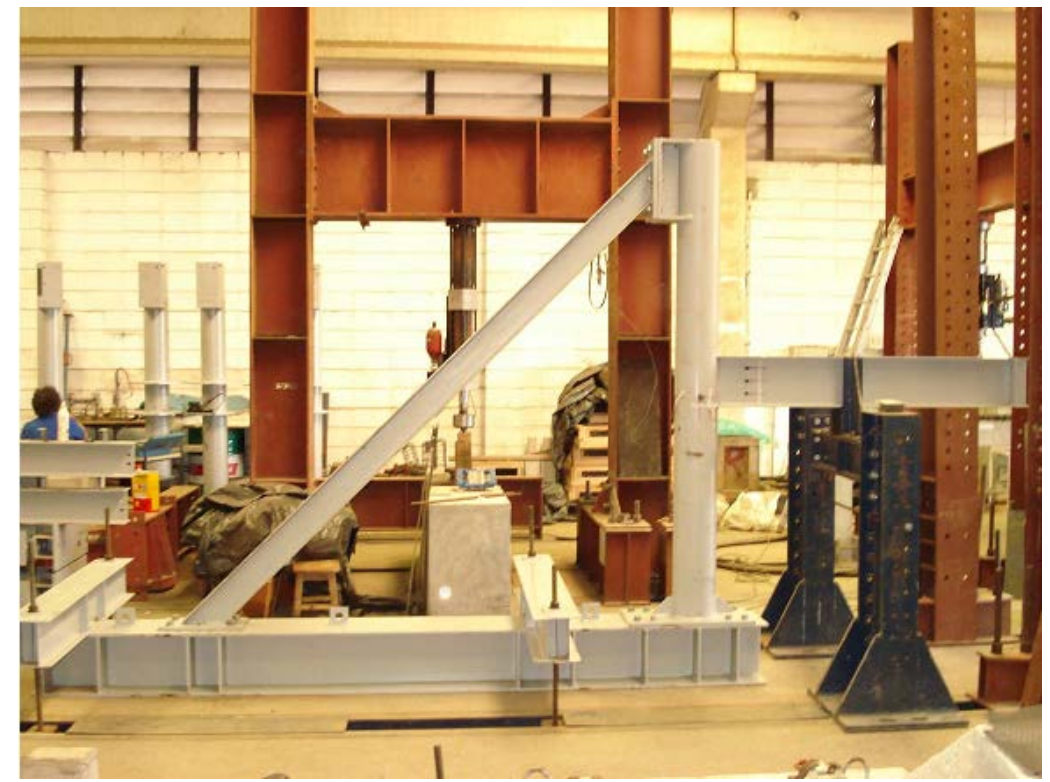

Fonte: Masioli (2011).

Figura 9 - Corte da seção transversal do pilar com vista para o diafragma externo

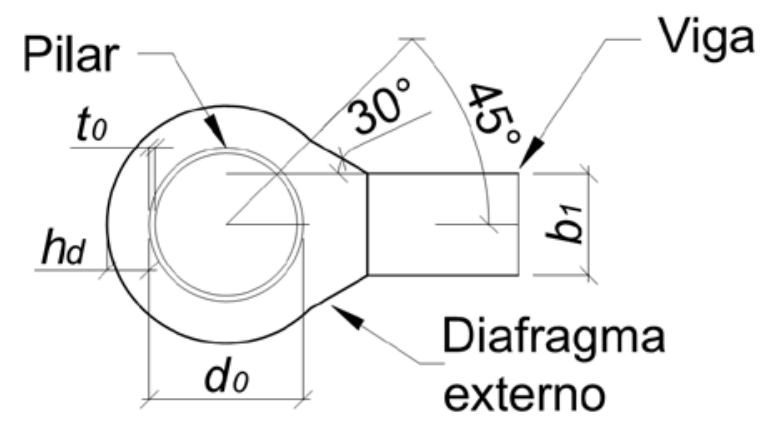


Figura 10 - Corte da seção longitudinal: pilar, viga e diafragma externo

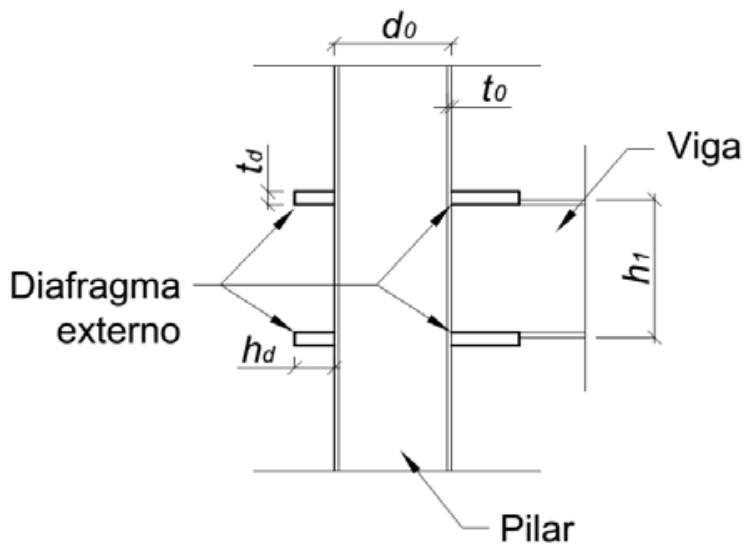

Para as geometrias do diafragma externo, têm-se alguns limites estabelecidos pelo Cidect-DG9 (KUROBANE et al., 2004), conforme as Equações 1,2 e 3. Junto a esses dados é apresentada também a investigação das larguras e espessuras além desses limites. A seguir temos as verificações em cada item.

(a) a primeira verificação é exclusiva ao pilar e correspondente à relação de seu diâmetro, $\mathrm{d}_{0}$, com sua espessura, $\mathrm{t}_{0}$. Com $\mathrm{d}_{0}=219,1 \mathrm{~mm}$ e $\mathrm{t}_{0}=8,2 \mathrm{~mm}$, tem-se (Eq. 1):

$14 \leq \frac{\mathrm{d}_{0}}{\mathrm{t}_{0}} \leq 36$

$\frac{\mathrm{d}_{0}}{\mathrm{t}_{0}}=26,71$, o que demonstra que o pilar utilizado nesta pesquisa atende a esse intervalo de validade.

(b) a segunda verificação é entre a largura do diafragma externo, $\mathrm{h}_{\mathrm{d}}$, e o diâmetro do pilar, $\mathrm{d}_{0}$ (Eq. 2):

$0,05 \leq \frac{\mathrm{h}_{\mathrm{d}}}{\mathrm{d}_{0}} \leq 0,14$

Com o valor do diâmetro do pilar, $\mathrm{d}_{0}$, conhecido, tem-se o intervalo permitido para a variação da largura do diafragma externo, $\mathrm{h}_{\mathrm{d}}$ : $10,95 \leq \mathrm{h}_{\mathrm{d}} \leq$ 30,67 .

Para essa análise é adotada a largura de $10 \mathrm{~mm}$, com acréscimos de $5 \mathrm{~mm}$ a partir desse valor até $70 \mathrm{~mm}$, limite em função da metade da largura da mesa da viga (73 mm).

A terceira verificação é a relação entre a espessura do diafragma externo, $\mathrm{t}_{\mathrm{d}}$, e a espessura da parede do pilar, $t_{0}$ (Eq. 3).

$0,75 \leq \frac{t_{d}}{t_{0}} \leq 2,0$

Eq. 3

Como a espessura do pilar, $\mathrm{t}_{0}$, é igual a $8,2 \mathrm{~mm}$, o intervalo de validade para a espessura do diafragma, $\mathrm{t}_{\mathrm{d}}$ é $6,15 \leq \mathrm{td} \leq 16,4$.
A dimensão adotada é a partir de $6 \mathrm{~mm}$, com acréscimos de $2 \mathrm{~mm}$ até o valor máximo de $20 \mathrm{~mm}$, limite como referência ao dobro da espessura da mesa da viga (18,2 mm).

Após as verificações e possibilidades para a geometria do diafragma externo, são mostradas na Tabela 5 as dimensões desse enrijecedor consideradas nesta análise.

Na Figura 11 é mostrado um exemplo da geometria do modelo numérico das ligações com diafragma externo utilizando o recurso da projeção da espessura no elemento de casca (Shell 281).

\section{Resultados e discussões}

Após a conceituação do modelo numérico é feita a investigação da influência da malha e de seu refinamento no resultado da convergência para a dimensão do elemento finito e validação. Em seguida, processa-se o estudo paramétrico da ligação com o diafragma externo.

\section{Estudo de convergência de malha e validação do modelo numérico}

Primeiramente é avaliado o número mínimo de elementos finitos em função da dimensão do elemento, compatível com a invariabilidade da força máxima absorvida na extremidade da viga do modelo, conforme mostrado na Figura 12, onde também é apresentado o tempo de processamento. Na Tabela 6 tem-se a dimensão adotada do elemento finito.

Na Figura 13 é mostrado o modelo numérico final para a geometria dos elementos obtido através de análise de convergência. 
Tabela 5 - Dimensões adotadas para o diafragma externo - em destaque os valores além dos limites do Cidect

\begin{tabular}{c|c|c}
\hline $\begin{array}{c}\text { Espessura }-\mathbf{t}_{\mathbf{d}} \\
(\mathbf{m m})\end{array}$ & $\begin{array}{c}\text { Largura }-\mathbf{h}_{\mathbf{d}} \\
(\mathbf{m m})\end{array}$ & $\begin{array}{c}\text { Total de modelos } \\
\text { numéricos }\end{array}$ \\
\hline & $\mathbf{1 0}$ & \\
& 15 & \\
$\mathbf{6}$ & 20 & \\
$\mathbf{8}$ & 25 & \\
10 & 30 & 104 \\
12 & $\mathbf{3 5}$ & \\
14 & $\mathbf{4 0}$ & \\
16 & $\mathbf{4 5}$ & \\
18 & $\mathbf{5 0}$ & \\
20 & $\mathbf{5 5}$ & \\
& $\mathbf{6 0}$ & \\
& $\mathbf{6 5}$ & \\
\hline
\end{tabular}

Figura 11 - Modelos numéricos para as dimensões máxima e mínima da ligação com diafragma externo

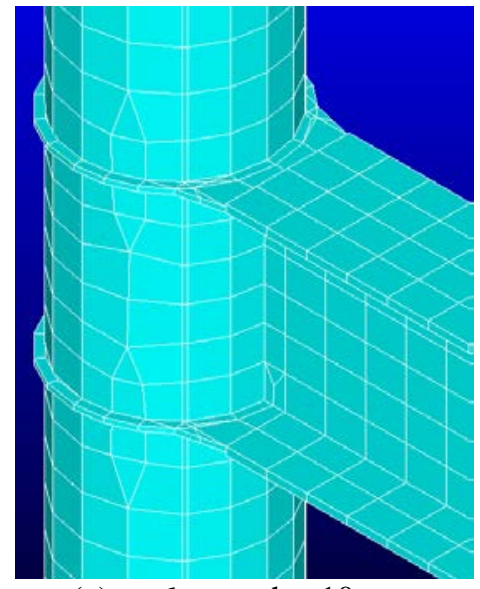

(a) $t_{d}=6 \mathrm{~mm}$ e $h_{d}=10 \mathrm{~mm}$

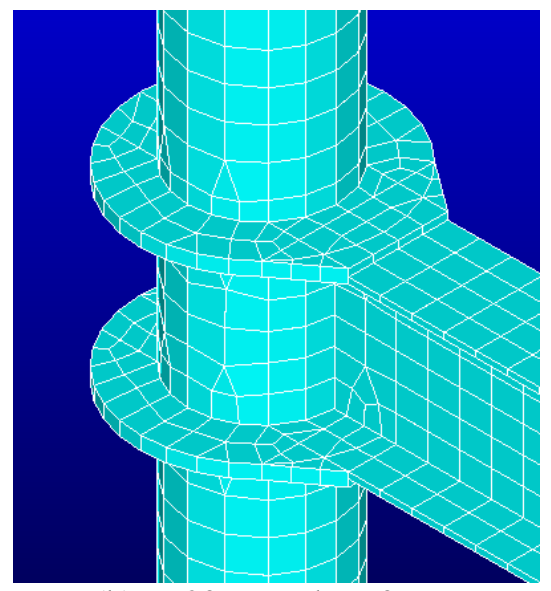

(b) $t_{d}=20 \mathrm{~mm}$ e $h_{d}=70 \mathrm{~mm}$

Figura 12 - Análise de convergência do modelo numérico TCR-W

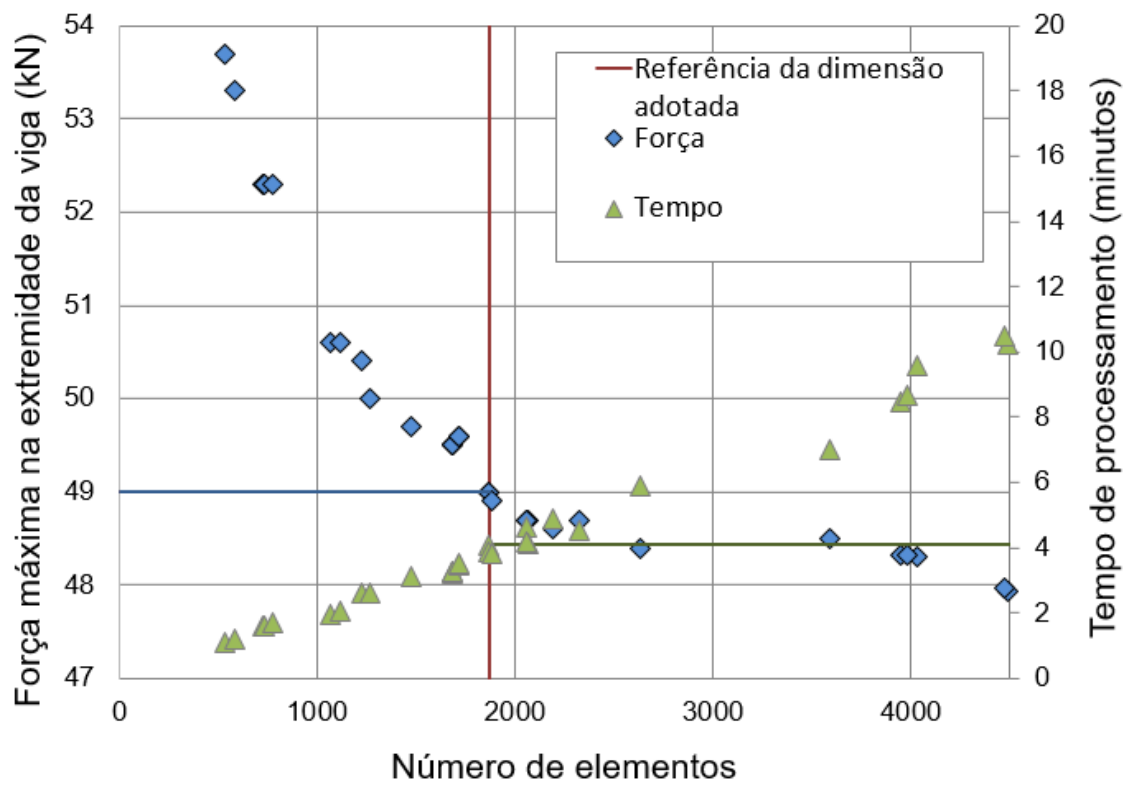


Tabela 6 - Características numéricas do modelo

\begin{tabular}{|c|c|c|c|c|}
\hline \multirow{2}{*}{ Força $(\mathbf{k N})$} & \multicolumn{2}{|c|}{ Dimensão do elemento (mm) } & \multirow{2}{*}{$\begin{array}{l}\text { Número de } \\
\text { elementos }\end{array}$} & \multirow{2}{*}{$\begin{array}{c}\text { Tempo de processamento } \\
\text { (minutos) }\end{array}$} \\
\hline & Padrão & Refinado & & \\
\hline 49,0 & 95,0 & 23,75 & 1.862 & 4,09 \\
\hline
\end{tabular}

Figura 13 - Modelo numérico TCR-W

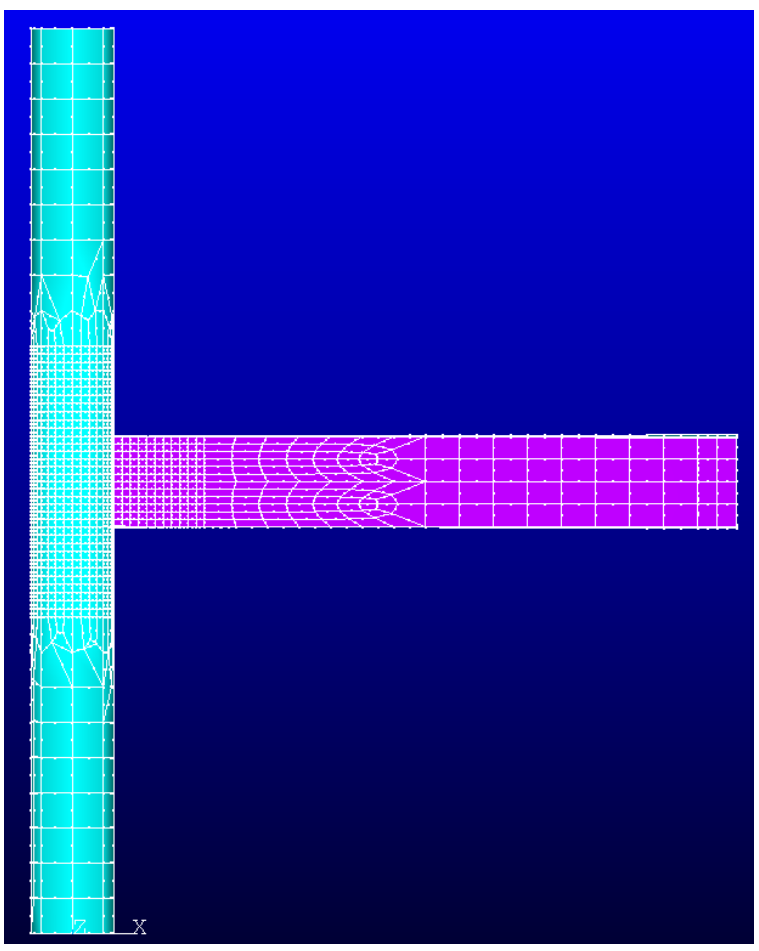

Após a definição quanto aos elementos e suas dimensões, é feita a validação do modelo numérico através de comparativo com alguma análise experimental. Neste trabalho é utilizado o comportamento do protótipo TCR-W de Masioli (2011) como referência, composto de uma ligação simples e sem diafragma externo, em que se aplica uma força na extremidade da viga em balanço. Na Figura 14 são mostrados os resultados numéricos e experimentais desses dados, e na Tabela 7 , a razão entre os valores máximos para força resistente da ligação - o qual certifica a modelagem desta pesquisa, tendo por referência a validação feita por Winkel (1998) - base para o Cidect-DG9 (KUROBANE et al., 2004) - em estudo similar, que nesta mesma razão obteve o valor de 1,16.

\section{Ligação simples e com o diafragma externo}

A primeira análise comparativa é quanto às tensões de von Mises. Ao se aplicar à ligação com diafragma externo a mesma força resistente da ligação simples, igual a 49,0 kN, na extremidade da viga verifica-se, de acordo com o mostrado na Figura 15, o alívio das tensões proporcionado pela presença desse enrijecedor - para a maior largura e espessura deste estudo - onde se constata a redução da tensão máxima na viga para o pilar.

Esse resultado demonstra a eficiência do diafragma externo e atende ao propósito nesta pesquisa, que é a mitigação dos efeitos causados pela concentração de tensões para esse tipo de ligação. Na Figura 16 destaca-se a interface da ligação.

Ademais, na Figura 17 tem-se a influência do diafragma externo na redução da rotação da ligação - inclusive para pequenas dimensões. Esses dados são obtidos a partir de um ponto na parte superior da interface entre o diafragma externo e a viga, o que comprova a afirmação de Wakabayashi, Sasaki e Kishima (1971) de que mesmo apenas a presença do diafragma externo influencia consideravelmente o comportamento da ligação 
Figura 14 - Força e deslocamento na extremidade da viga

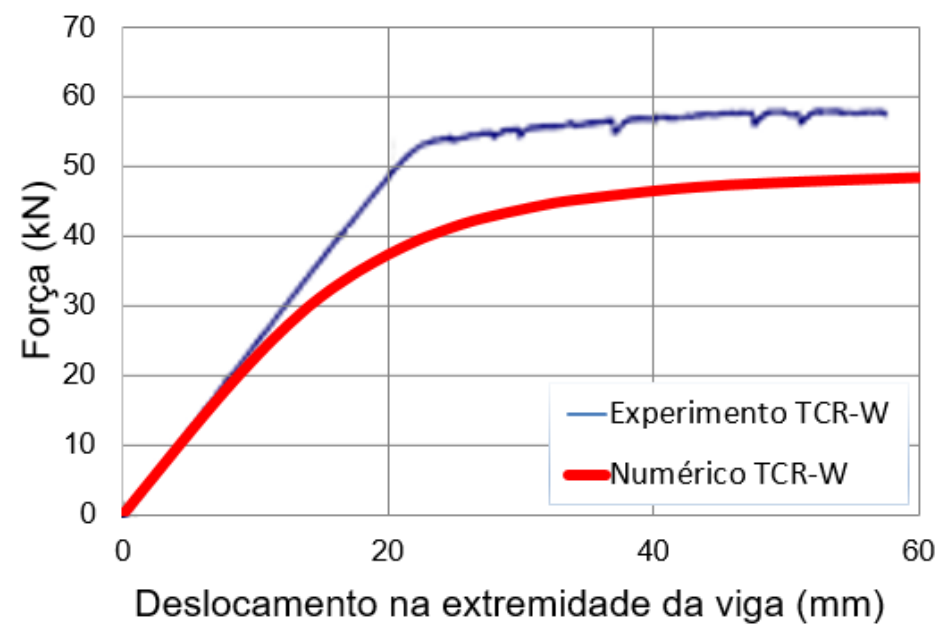

Tabela 7 - Força máxima na extremidade da viga

\begin{tabular}{c|c|c}
\hline \multicolumn{2}{c|}{ Força máxima (kN) } & $\begin{array}{c}\text { Numérico/ } \\
\text { Experimental }\end{array}$ \\
\hline Numérico & Experimental & 1,17 \\
\hline 49,0 & 57,5 & \\
\hline
\end{tabular}

Figura 15 - Tensões de von Mises (MPa) no modelo numérico

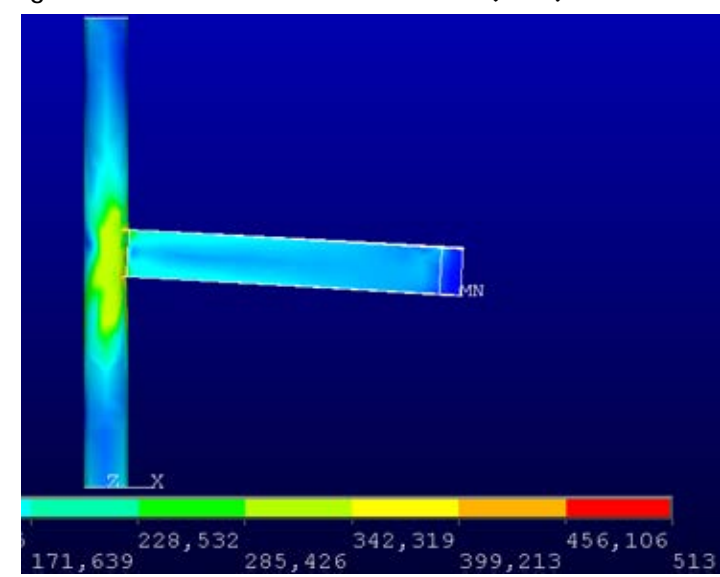

(a) TCR-W (513 MPa, viga)

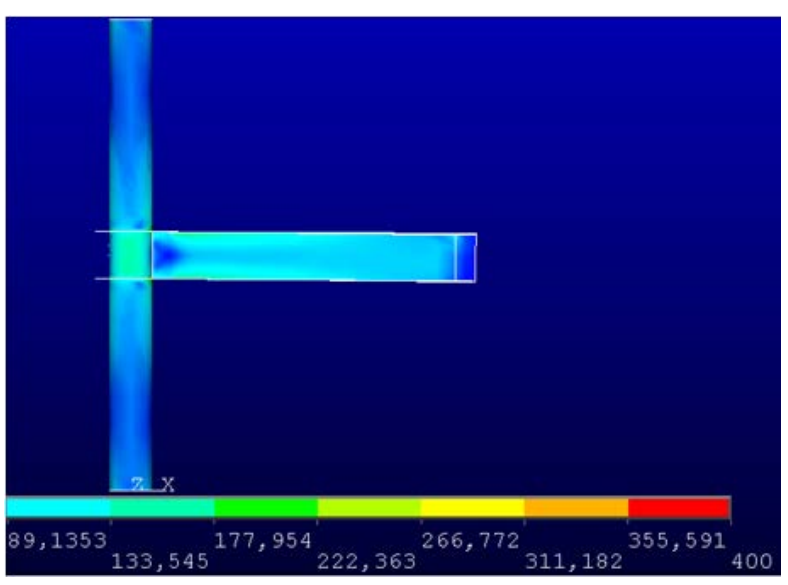

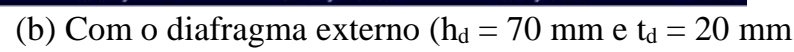
(400 MPa, pilar)

Figura 16 - Tensões de von Mises (MPa) na ligação: (a); e (b)

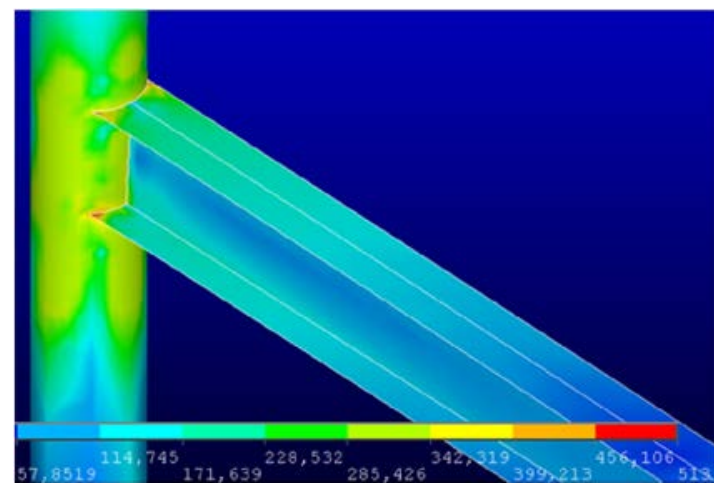

(a) TCR-W

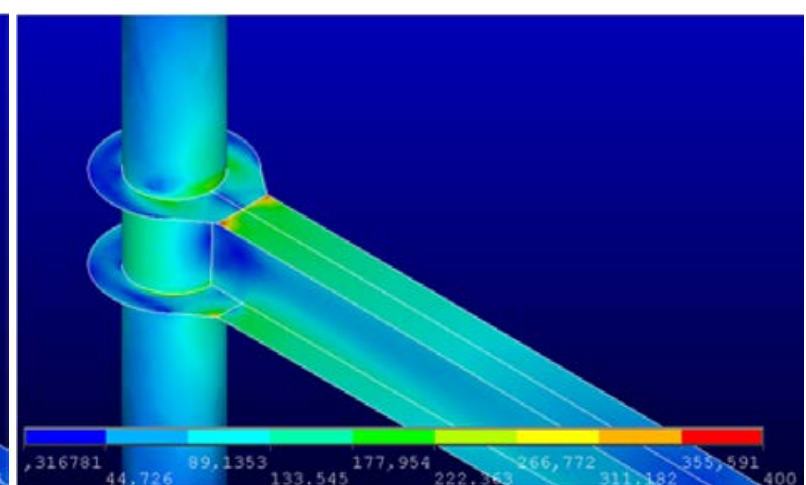

(b) Diafragma ex terno $\left(\mathrm{h}_{\mathrm{d}}=70 \mathrm{~mm}\right.$ e $\left.\mathrm{t}_{\mathrm{d}}=20 \mathrm{~mm}\right)$ 
Figura 17 - Rotação da ligação para $F=49,0$ kN aplicado na extremidade da viga

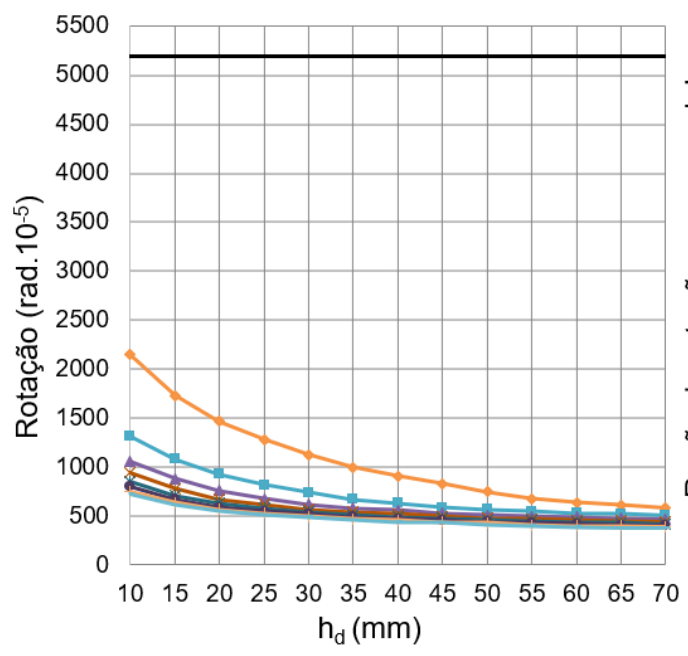

\section{Resistência e rigidez máxima da ligação com o diafragma externo}

Após o estudo comparativo da influência do diafragma externo na ligação para um mesmo nível de carga, nota-se a possibilidade de maiores carregamentos ao modelo. Nesse sentido são apresentados na Figura 18 os comportamentos numéricos das ligações quando submetidos à força máxima na extremidade da viga até a perda da estabilidade estrutural - o propósito é verificar a uniformidade do comportamento das ligações caracterizado em suas curvas momento-rotação.

\section{Resistência máxima da ligação com o diafragma externo}

Primeiro é feita a investigação da resistência máxima com as diferentes geometrias do diafragma externo no sentido de estudar o local da falha das ligações através da rotação relativa, conforme mostrado na Figura 19, entre as extremidades (ligação com diafragma externo e balanço) para o momento máximo aplicado.

Assim, verifica-se a partir do valor do momento próximo a $160,0 \mathrm{kNm}$ que as relações entre as rotações nas extremidades da viga deixam de ser proporcionais. Essa condição corresponde à ocorrência da falha na viga, condição ideal para a escolha de um sistema estrutural, pois o colapso deixa de ocorrer na ligação e passa a ocorrer em seus perfis. A partir do conhecimento do local da falha, é apresentada na Figura 20 a resistência máxima ao momento da ligação com o diafragma externo e o comparativo com o modelo TCR-W.

É verificado o acréscimo considerável da resistência da ligação com o diafragma externo em

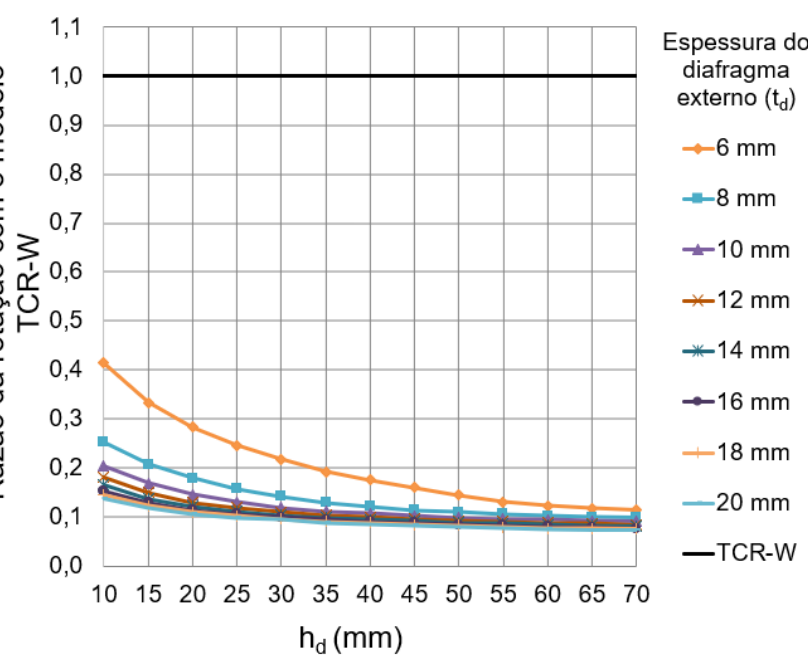

comparação ao modelo TCR-W, sendo possível até 155\% de acréscimo - essa limitação é em função da ocorrência da falha na viga a partir de $110 \%$. O destaque é a influência do aumento da resistência proporcionado pelo diafragma externo mesmo quando suas dimensões estão abaixo da espessura da mesa da viga, $b_{f}$ igual a 9,1 mm com $t_{d}$ igual a 6 mm, e ainda assim há aumento da resistência da ligação em 5\%.

Ademais é feito um estudo dos resultados para correlação da geometria do diafragma externo com o momento máximo resistente. Primeiramente é analisada a relação entre a largura do diafragma externo e sua espessura, o que corresponde à metade da área da seção transversal, e posteriormente é feito o acréscimo do expoente desses dois termos de forma a buscar um comportamento conhecido. Nesse caso, o valor obtido para esse fim é para a largura e espessura igual a 1 e 2 respectivamente, conforme ilustrado na Figura 21, onde os pontos se aproximam de um comportamento linear.

Assim, para $t_{d}^{2} \cdot h_{d}$ há proporcionalidade no aumento da resistência da ligação, em que a largura do diafragma externo é a que mais influência. Também se pode afirmar que há correlação na consideração das geometrias dos valores além dos limites do Cidect, o que sugere a reavaliação de seus termos.

\section{Rigidez inicial da ligação com o diafragma externo}

Quanto à rigidez inicial da ligação, que é anterior ao patamar de escoamento do aço, o diafragma externo também contribui consideravelmente em seu comportamento, de acordo com o apresentado na Figura 22. 
Figura 18 - Principais curvas momento-rotação

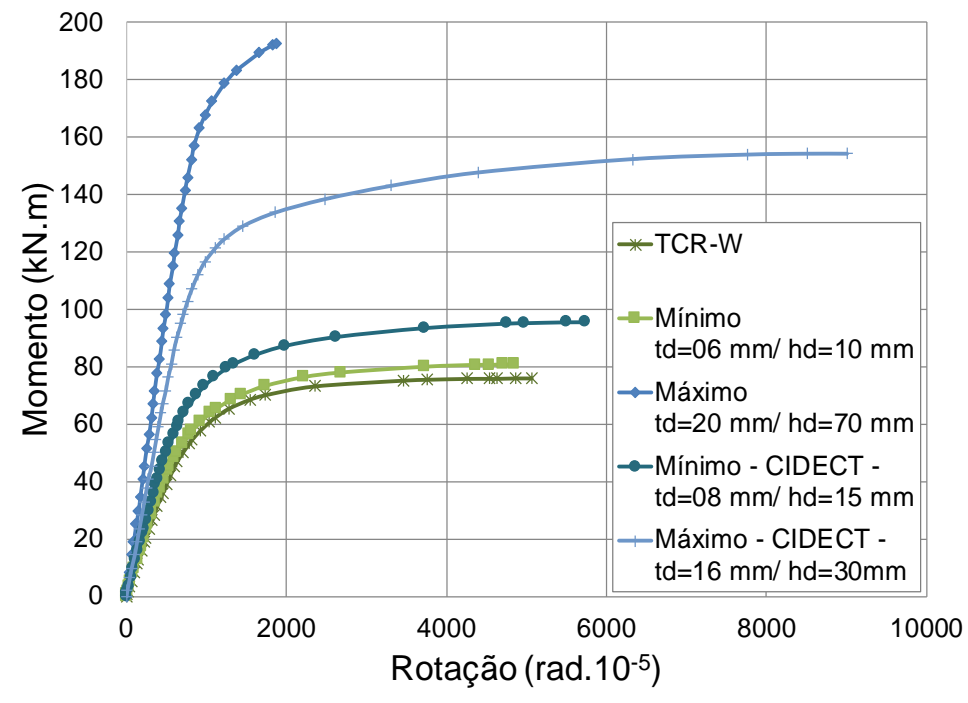

Figura 19 - Resistência máxima para o intervalo da largura, $h_{d}$, entre 10 mm e 70 mm Momento (kN.m)

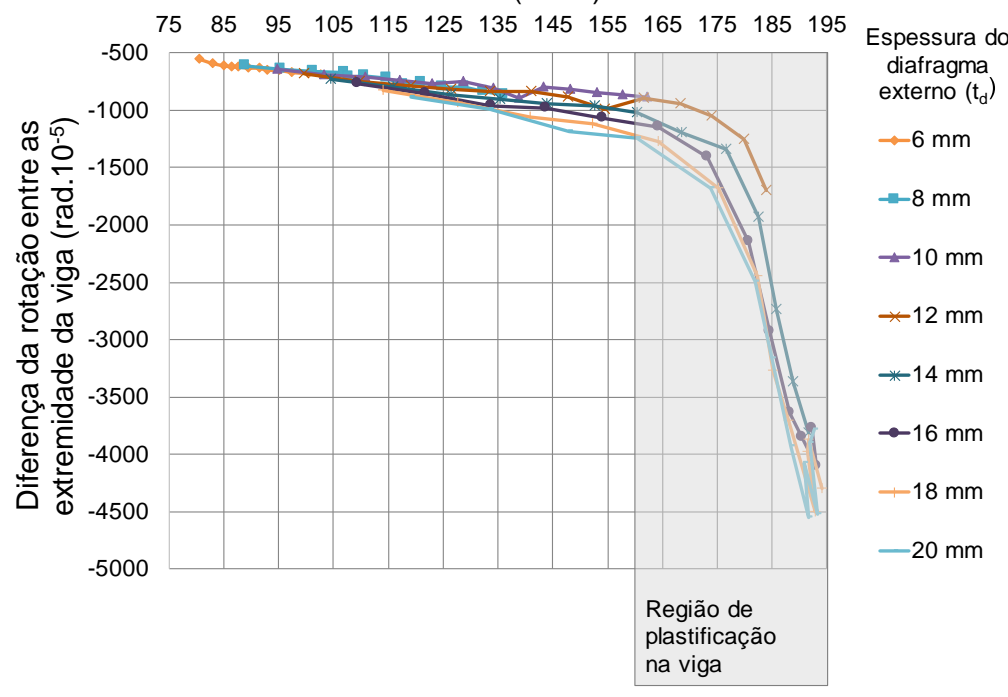

Figura 20 - Resistência máxima da ligação

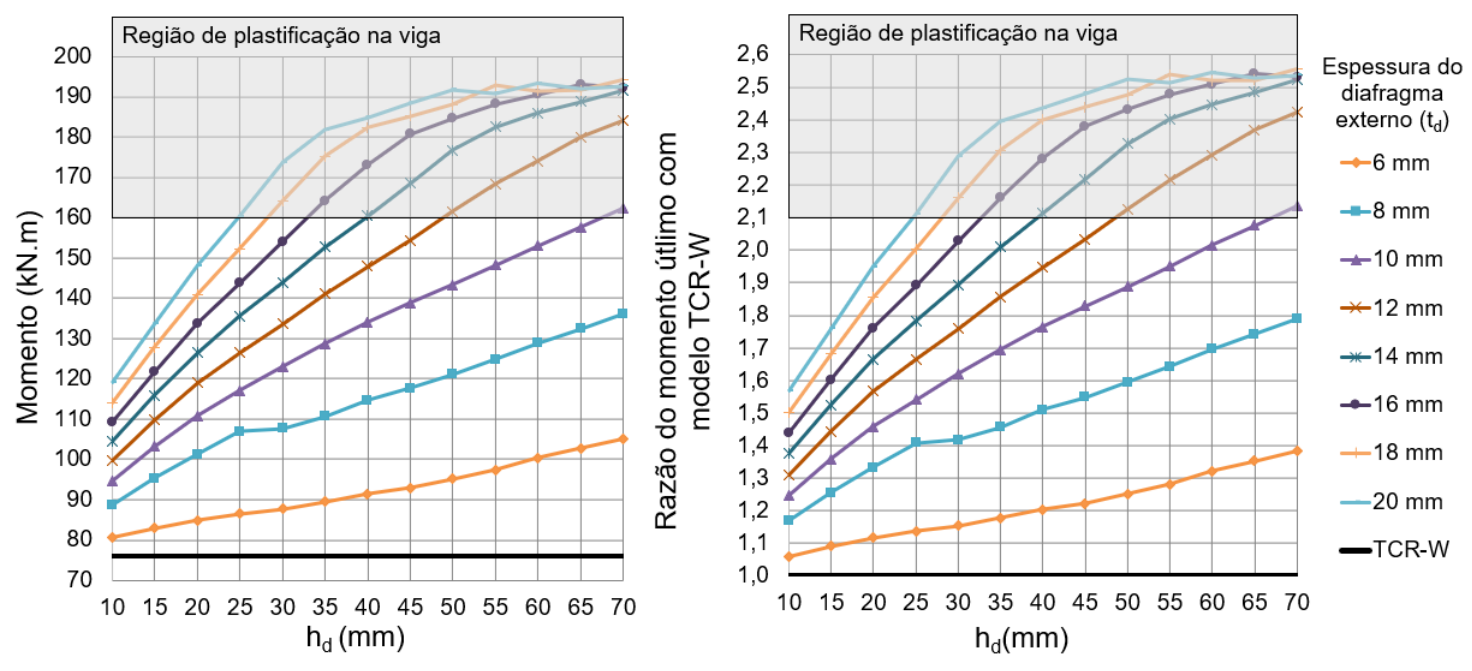


Figura 21 - Resistência máxima das ligações com diafragma externo

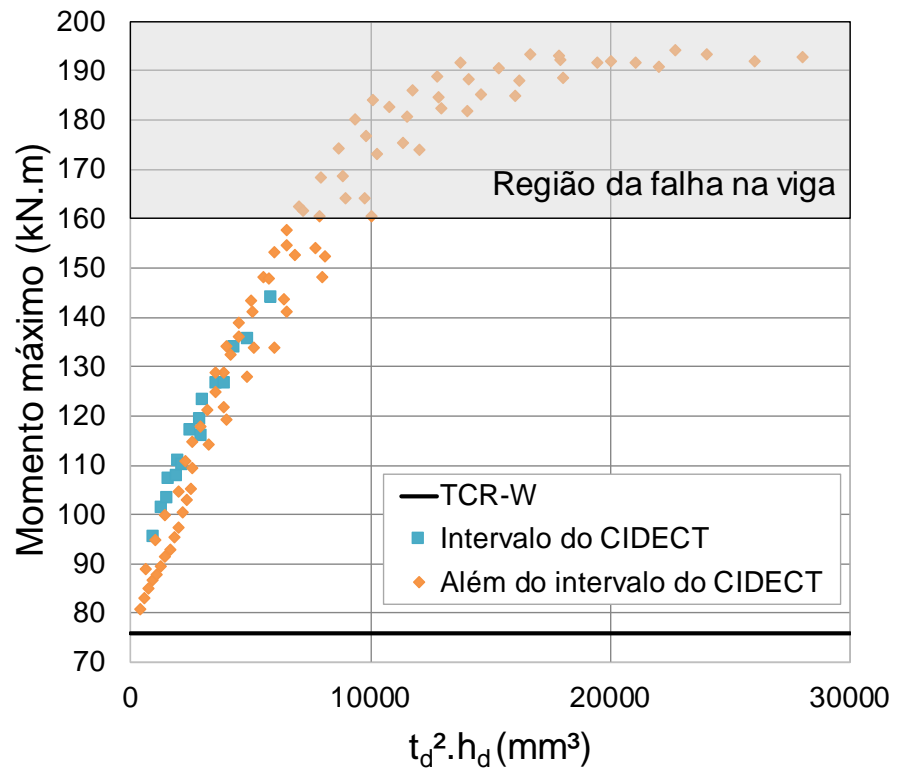

Figura 22 - Rigidez inicial da ligação com diafragma externo

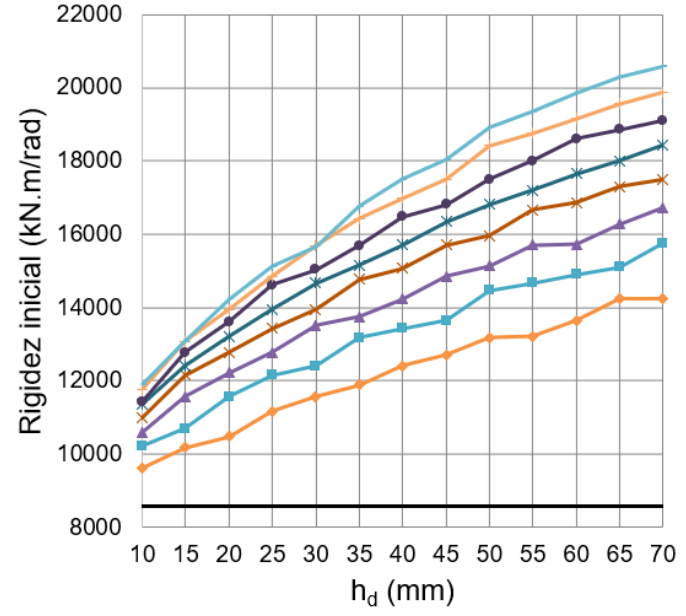

Na comparação com o modelo TCR-W, tem-se a possibilidade de enrijecer em até $140 \%$ a ligação. Para a situação da dimensão menor que a espessura da mesa da viga, o acréscimo é de $10 \%$ e comprova a eficácia do diafragma externo na ligação. Nota-se também para a rigidez inicial a proporcionalidade de seu comportamento com a área do diafragma externo, $\mathrm{t}_{\mathrm{d}}:-\mathrm{h}_{\mathrm{d}}$, conforme mostrado na Figura 23.

Observa-se ainda a correlação de seus valores com a metade da área da seção transversal do diafragma externo, diferentemente da situação para resistência máxima. Para os valores além dos limites do CidectDG9 (KUROBANE et al., 2004), seguindo a mesma tendência do momento resistente máximo, verifica-se também a concordância dos resultados, o que novamente sugere a reavaliação de suas margens de aplicação.

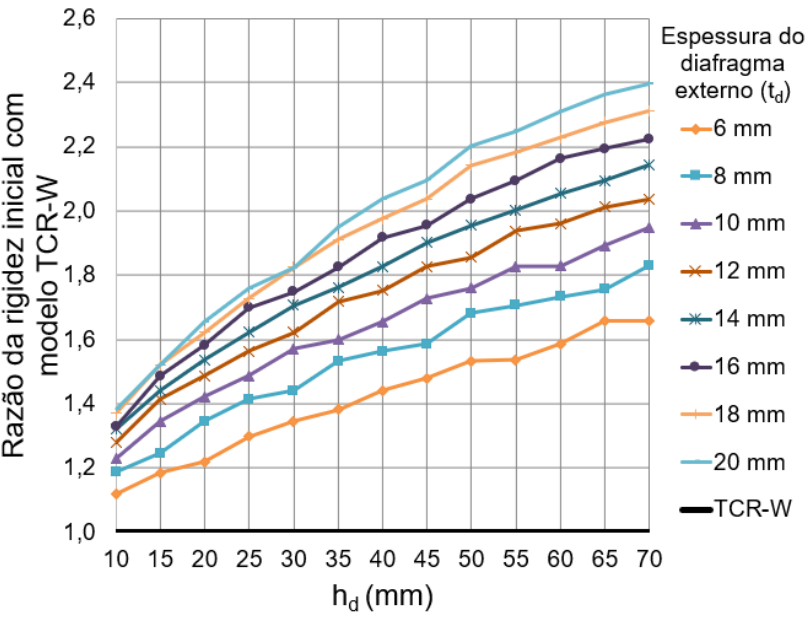

\section{Considerações finais}

A partir dos resultados apresentados, conclui-se com este trabalho a eficácia do uso do diafragma externo na ligação do sistema estrutural com viga de seção I e pilar tubular de seção circular, com aumento expressivo na ligação do momento resistente e redução da rotação da viga junto ao pilar. Além disso, é notório o comportamento linear desses parâmetros conforme variação geométrica do diafragma externo, o que aumenta a confiabilidade de seu uso e possibilita alterar a ocorrência da falha ao utilizar geometrias robustas do diafragma externo, sendo viável seu acontecimento na viga - avanço expressivo para esse sistema estrutural, que é caracterizado em sua simples ligação como rotulado. 
Figura 23 - Rigidez inicial das ligações

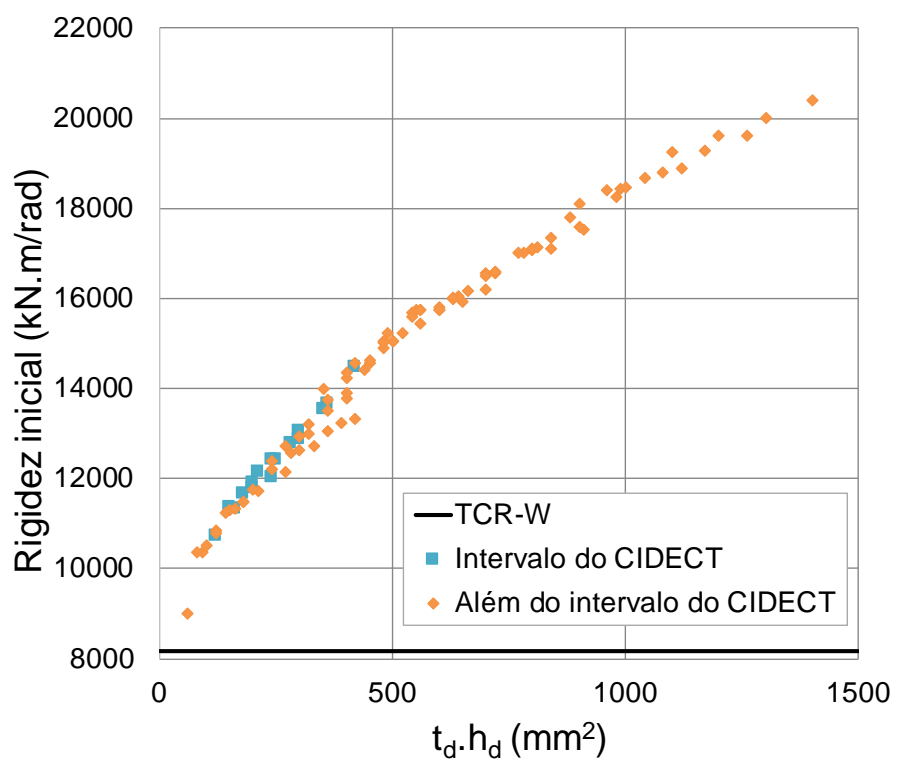

Em concordância com esses benefícios estruturais, as altas tensões no pilar são reduzidas para médias abaixo do escoamento de seu aço. Para a geometria apresentada pelo Cidect-DG9, segundo Kurobane et al. (2004), através desta pesquisa verifica-se a necessidade de uma nova avaliação de seus limites de uso, sendo admissível aumentar a faixa de larguras e espessuras da aplicação do diafragma externo.

Diante disso, para o sistema estrutural com pilar tubular de seção circular e viga de seção I, tem-se inicialmente um limite de uso em função das características da simples ligação, o que limita a escolha desse modelo. Porém, com a adoção do diafragma externo em suas ligações, possibilita-se aos arquitetos e engenheiros melhor controle comportamental (força máxima e rigidez) e, dessa forma, uma maior utilização desse sistema estrutural nas edificações.

\section{Referências}

\section{AMERICAN NATIONAL STANDARDS INSTITUTE/AMERICAN INSTITUTE OF STEEL CONSTRUCTION. ANSI/AISC 360: specification for structural steel buildings. Chicago, 2010.}

ANSYS User’s Manual: theory,Vol. XI. Swanson Analysis Systems, 1999.

\section{ASSOCIAÇÃO BRASILEIRA DE NORMAS} TÉCNICAS. NBR 16239: projeto de estruturas de aço e de estruturas mistas de aço e concreto de edificações com perfis tubulares. Rio de Janeiro, 2013.
ATLAS TUBE. [Imagem]. Disponível em: $<$ www.atlastube.com>. Acesso em: 17 out. 2013.

CARVALHO, P. H. Avaliação Numérica do Comportamento Estrutural de Ligação Entre Pilar de Seção Tubular Circular e Viga de Seção “I”. Ouro Preto, 2005. Dissertação (Mestrado em Engenharia Civil) - Escola de Minas, Universidade Federal de Ouro Preto, Ouro Preto, 2005.

EUROPEAN UNION. Eurocode 3: design of steel structures: part 1-1: general rules and rules for buildings. Bélgica, 2005a.

EUROPEAN UNION. Eurocode 3: design of steel structures: part 1-8: design of joints. Bélgica, $2005 b$

\section{FREITAS, P. C. B. Análise Numérica de} Ligações Metálicas Viga-Coluna Com Coluna Tubular Circular. São Carlos, 2009. Dissertação (Mestrado em Engenharia Civil) - Escola de Engenharia de São Carlos, Universidade de São Paulo, São Carlos, 2009.

KAMBA, T.; KANATANI, H. Design Formulae For CHS Column-to-Beam Connections With Exterior Diaphragms. In: INTERNATIONAL SYMPOSIUM ON TUBULAR STRUCTURES, 5., Nottingham, 1993. Proceedings... Nottingham, 1993.

KUROBANE, Y. et al. CIDECT Design Guide 9: design guide for structural hollow section column. Köln: CIDECT; Verlag TÜV Rheinland, 2004. 
MAGGI, Y. I. Análise do Comportamento Estrutural de Ligações Parafusadas Viga-Pilar Com Chapa de Topo Estendida. São Carlos, 2004. Tese (Doutorado em Engenharia Civil) Escola de Engenharia de São Carlos, Universidade de São Paulo, São Carlos, 2004.

MASIOLI, C. Z. Análise Teórica e Experimental de Ligações em Aço Entre Pilar Tubular de Seção Circular e Viga de Seção I. São Carlos, 2011. Dissertação (Mestrado em Engenharia Civil) - Escola de Engenharia de São Carlos, Universidade de São Paulo, São Carlos, 2011.

PEREIRA, D. H. F. Análise do Comportamento Estrutural de Ligações em Aço Entre Viga de Seção I e Pilar de Seção Tubular Circular. São Carlos, 2013. Dissertação (Mestrado em Engenharia Civil) - Escola de Engenharia de São Carlos, Universidade de São Paulo, São Carlos, 2013.
WAKABAYASHI, M.; SASAKI, R.; KISHIMA, Y. An Experimental Study on Centrifugally-Cast Steel Pipe to h-Beam Connections Annuals.

Disaster Prevention Research Institute, Kyoto, v. 14, p. 343-369, apr. 1971.

WINKEL, G. D. The Static Strength of I-Beam to Circular Hollow Section Column

Connections. Delft, 1998. Tese (PhD) - Faculty of Civil Engineering and Geosciences, Delft University of Technology, Delft, 1998.

\section{Agradecimentos}

Agradecemos ao Programa de Pós-Graduação em Engenharia Civil da Universidade Federal do Espírito Santo pelo apoio a esta pesquisa.

Felipe Botelho Coutinho

Departamento de Engenharia Civil | Universidade Federal do Espírito Santo | Av. Fernando Ferrari, 514, Goiabeiras | Vitória - ES - Brasil | CEP 29075-910 | Tel.: (27) 4009-2656 | E-mail: felipecoutinho@msn.com

Walnório Graça Ferreira

Departamento de Engenharia Civil | Universidade Federal do Espírito Santo | Tel.: (27) 4009-2128 | E-mail: walnorio@gmail.com

Macksuel Soares de Azevedo

Departamento de Engenharia Civil | Universidade Federal do Espírito Santo | Tel.: (27) 4009-2128 | E-mail: macksuel.azevedo@gmail.com

Revista Ambiente Construído

Associação Nacional de Tecnologia do Ambiente Construído

Av. Osvaldo Aranha, 99 - 3o andar, Centro

Porto Alegre - RS - Brasil

CEP 90035-190

Telefone: +55 (51) 3308-4084

Fax: +55 (51) 3308-4054

www. seer. ufrgs. br/ ambienteconstruido

E-mail: ambienteconstruido@ufrgs.br

c) (i) This is an open-access article distributed under the terms of the Creative Commons Attribution License. 